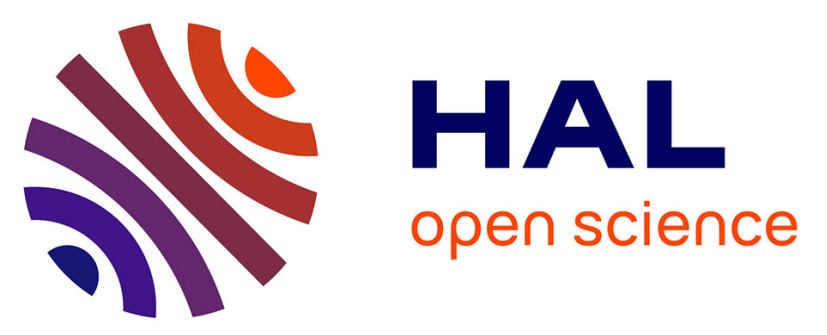

\title{
A multi-family offline SPE LC-MS/MS analytical method for anionic, cationic and non-ionic surfactants quantification in surface water
}

Laure Wiest, Barbara Giroud, Azziz Assoumani, François Lestremau, Emmanuelle Vulliet

\section{To cite this version:}

Laure Wiest, Barbara Giroud, Azziz Assoumani, François Lestremau, Emmanuelle Vulliet. A multifamily offline SPE LC-MS/MS analytical method for anionic, cationic and non-ionic surfactants quantification in surface water. Talanta, 2021, 232, pp.122441. 10.1016/j.talanta.2021.122441. hal03209496

\section{HAL Id: hal-03209496 \\ https://hal.science/hal-03209496}

Submitted on 27 Apr 2021

HAL is a multi-disciplinary open access archive for the deposit and dissemination of scientific research documents, whether they are published or not. The documents may come from teaching and research institutions in France or abroad, or from public or private research centers.
L'archive ouverte pluridisciplinaire HAL, est destinée au dépôt et à la diffusion de documents scientifiques de niveau recherche, publiés ou non, émanant des établissements d'enseignement et de recherche français ou étrangers, des laboratoires publics ou privés. 
A multi-family offline SPE LC-MS/MS analytical method for anionic, cationic and nonionic surfactants quantification in surface water

Laure Wiest $^{1 *}$, Barbara Giroud ${ }^{1}$, Azziz Assoumani $^{2}$, François Lestremau $^{2}$, Emmanuelle Vulliet $^{1}$

${ }^{1}$ Univ Lyon, CNRS, Université Claude Bernard Lyon 1, Institut des Sciences Analytiques, UMR 5280, 5 rue de la Doua, F-69100 VILLEURBANNE, France

${ }^{2}$ INERIS, Unité Méthodes et développements en Analyses pour l'Environnement, F-60550 VERNEUIL-EN-HALATTE, France

*Corresponding author: laure.wiest@isa-lyon.fr, +33(0)4 37423621 


\begin{abstract}
Of the large number of emerging pollutants discharged from wastewaters into surface waters, surfactants are among those with the highest concentrations. However, few monitoring in river waters of these substances have already been performed and only on a few families, mostly anionic.

This work aimed to develop a multi-family analytical strategy suitable for the quantification of low concentrations of surfactant in surface waters. Twelve families of surfactants, anionic, cationic and non-ionic were selected. Their quantification by liquid chromatography coupled with tandem mass spectrometry (LC-MS/MS) and their extraction by SPE were optimized by comparing different retention mechanisms. The best performances were obtained with a $\mathrm{C} 18$ grafted silica LC column and a hydrophilic-lipophilic balanced (HLB) polymeric SPE cartridge. The final analytical method was validated and applied for the quantification of surfactants in 36 river water samples. Method limits of quantification (LQ), intra and inter days precision and trueness were evaluated. With LQ between 15 and $485 \mathrm{ng} / \mathrm{L}$, and trueness over $80 \%$, this method was suitable for monitoring surfactants in surface water. Application on French river water samples revealed the presence of anionic, cationic and non-ionic surfactants with median concentrations from $24 \mathrm{ng} / \mathrm{L}$ for octylphenol ethoxylates (OPEO), up to $4.6 \mu \mathrm{g} / \mathrm{L}$ regarding linear alkylbenzene sulfonates (LAS).
\end{abstract}

\title{
Keywords
}

Anionic surfactant; cationic surfactant; non-ionic surfactant; surface water; SPE; LC-MS/MS; 


\section{Introduction}

Technological innovations in analytical chemistry, in particular mass spectrometry, and improved knowledge of man-made chemicals [1] (ECHA 2019) have led to questions about the presence of micropollutants in river water. Among this wide variety of pollutants, surfactants are among the most largely used and produced. For example, linear alkylbenzene sulfonates (LAS) are widely used in various detergent formulations, including liquid and powder detergents, dishwashing liquids and tablets, car washes and hard surface cleaners. Industrial detergents and cleaners also often contain them, which implies contaminations even in analytical instruments and materials [2]. Consequently, their concentrations in wastewater treatment plant (WWTP) influents and effluents are among the highest [3]. There is a very large number of surfactant molecules. Amphiphilic, they are often classified according to the ionic charge of their polar function, anionic, cationic or non-ionic.

Among this diversity of substances, previous studies only addressed a limited number of homologues or isomers and most of monitorings were carried out in wastewaters [4]. Only a few have been monitored in surface waters: the anionic surfactants, LAS [5], alkylethersulfate (AES) and alkylsulfate (AS) [6], the non-ionic alkylphenol ethoxylates (APEO) [7], and the cationic benzalkonium chloride (BAC) [2] and dialkyldimethyl ammonium chloride (DDAC) [8]. Conversely, triethanolamine esterquat (TEAQ) are the most produced and/or imported cationic surfactants in Europe with more than 100,000 tons per year [1] (ECHA 2019) but no data about their occurrence in the aquatic environment is available in the literature. There is therefore a lack of knowledge about the presence of surfactants in receiving environments. One of the analytical difficulties that could partly explain this absence of data is the lack of analytical 
standards, which are essential for method development, validation then quantification. Indeed, surfactants are often a mixture of homologues or isomers.

Due to the large number of surfactants and low concentrations in the environment [6], analysis in surface waters needs multi-residue and sensitive analytical strategies. Existing analytical protocols for surfactants in surface waters were mostly based on solid phase extraction (SPE) followed by liquid chromatography coupled with tandem mass spectrometry (LC-MS/MS) [9]. They generally focused on only one type of surfactant, anionic $[6,10-13]$, cationic $[8,14]$ or non-ionic [15-18]. Very few analytical methods were developed and validated for more than one type of surfactant. Lara-Martin et al. [5] and Gomez and al. [19] developed methods for the simultaneous analysis of anionic and non-ionic surfactants in waters, respectively using $\mathrm{C} 18$ grafted silica and hydrophilic-lipophilic balanced (HLB) polymeric SPE cartridges. This latter cartridge was also used by Li et al. [2] to extract anionic and cationic surfactants. Finally, Bergé et al.[20] optimized an analytical method that allowed the quantification of the three types of surfactants, based on SPE with a solid phase that combines aminopropyl and C8 grafted silica. Nevertheless, this method was applied to WW and not to surface water.

Within this context, the aim of this study was to develop one multi-families method to extract and analyse cationic, anionic and non-ionic surfactants in surface waters. Twelve different families of surfactants were targeted including some substances that have not been analysed previously in the aquatic environment. Different kinds of LC columns and SPE cartridges were compared in order to reach the best sensitivity. Special care to avoid contamination issues was undertaken at all stages of the analysis. Finally, the optimized analytical method was validated and applied to 36 river water samples. 


\section{Materials and methods}

\subsection{Target compounds, chemicals and materials}

The molecules targeted in this study include 9 anionic, 7 non-ionic and 9 cationic surfactants, making a total of 25 individual substances which represents 12 families of surfactants (Table S1). The anionic surfactants targeted in this study belong to three families: linear alkylbenzene sulfonate (LAS), alkylethersulfate (AES) and alkylsulfate (AS). Non-ionic surfactants belong to three families: octylphenol ethoxylate (OPEO), cocamides and surfynol. The cationic and amphoteric surfactants targeted in this study belong to five families: benzalkonium chloride (BAC), dialkyldimethyl ammonium chloride (DDAC), alkylpyridinium, triethanolamine esterquat (TEAQ) and amidoamines. Finally, one amphoteric surfactant belong to alkylbetaines.

The suppliers of standards are reported in Table S2. Five of these standards (in grey in Table S2) consist of mixture of homologues or isomers. Of these, the BAC- $\mathrm{C}_{12}$ and $\mathrm{C}_{14}$ standard was characterised by the supplier as containing $64.9 \%$ and $31.2 \%$ BAC- $\mathrm{C}_{12}$ and $\mathrm{C}_{14}$ respectively. The compositions of the other four analytical standards (LAS C10-C13, laureth sulfate $\left(\mathrm{C}_{12} \mathrm{EO}_{0}\right.$ ${ }_{2} \mathrm{~S}$ ), OPEO and TEAQ) were not provided by the supplier. Consequently, as already reported $[4,17]$, the relative percentages of isomers or homologues were estimated by LC-MS. Standard solutions were analyzed by LC-MS and individual isomer or homologue concentrations were deduced from the areas of each, making the approximation that all isomers or homologues have identical response factors (Table S2). The surrogate standards, which are deuterated compounds, Benzyldimethyldecylammonium-d5 Chloride (BDDA-d5), Hexadecylpyridiniumd5 Bromide (HexPyr-d5) and Sodium Dodecyl-d25 Sulfate (SDS-d25), were supplied by CDN isotopes (purity $>98 \%$ ). Individual stock standard and surrogate standard solutions were prepared at a concentration of $200 \mathrm{mg} / \mathrm{L}$, by dissolving $2 \mathrm{mg}$ in $10 \mathrm{~mL}$ of methanol/water 50/50. After preparation, standards were stored in the dark at $4^{\circ} \mathrm{C}$. A mixture of these standards at 10 
$\mathrm{mg} / \mathrm{L}$, prepared in methanol/water $50 / 50$, stored at $4{ }^{\circ} \mathrm{C}$ was stable for three months. Diluted working standard solutions were prepared regularly and stored at $4^{\circ} \mathrm{C}$.

The suppliers of the reagents were: LC-MS grade formic acid and ammonium acetate (Biosolve-chemicals, Dieuze, France), LC-MS grade water (Fisher Chemical, Geel, Belgium), methanol and acetonitrile (Honeywell, Seelze, Germany), ammonium hydroxide (Merck KGaA, Saint Louis, USA) . MilliQ water was produced by a Millipore filtration system. Mineral water packaged in glass bottles was supplied by Evian ${ }^{\circledR}$ (Evian-les-Bains, France). Binder-free glass fiber filters, $0.7 \mu \mathrm{m}$ pore size, diameter $142 \mathrm{~mm}$ were supplied by Merck Millipore Ltd. (Carrigtwohill, Ireland). Glass fiber filters, field sample vials and glass tubes were calcined for 15 hours at $450^{\circ} \mathrm{C}$ before use.

\subsection{Solid Phase Extraction}

Solid Phase Extractions (SPE) were carried out with an automatic extractor AutoTrace ${ }^{\mathrm{TM}} 280$ (Thermo Fisher Scientific, Waltham, MA, USA). Three different SPE cartridges were tested: Oasis $^{\text {TM }}$ HLB (Waters $@$, Milford, USA), 6 mL, 150 mg, Strata-C18-ETM (Phenomenex@, Torrance, USA), $3 \mathrm{~mL}, 200 \mathrm{mg}$, and Cunax2 ${ }^{\mathrm{TM}}$ (United Chemical Technologies $\bigodot$, Bristol, USA) $3 \mathrm{~mL}, 200 \mathrm{mg}$. For SPE optimization, Each sample consisted of mineral water spiked with all standards at approximately $1 \mu \mathrm{g} / \mathrm{L}$ and each experiment was performed in triplicates. Conditioning, loading and elution protocols were based on Bergé et al. [20] and were as follows: first, the SPE cartridge was conditioned with $8 \mathrm{~mL}$ of methanol, $4 \mathrm{~mL}$ of LC-MS grade water and $4 \mathrm{~mL}$ of $0.1 \mathrm{M}$ phosphate buffer $(\mathrm{pH}=6)$. The phosphate buffer was composed of $13 \mathrm{~mL}$ of $1 \mathrm{M} \mathrm{K}_{2} \mathrm{HPO}_{4}$ and $87 \mathrm{~mL}$ of $1 \mathrm{M} \mathrm{KH}_{2} \mathrm{PO}_{4}$ per liter. Then, after the percolation of $250 \mathrm{~mL}$ of sample at $10 \mathrm{~mL} / \mathrm{min}$, the cartridge was rinsed with $5 \mathrm{~mL}$ of phosphate buffer and dried under nitrogen stream for $5 \mathrm{~min}$. Finally, two elution steps were done: a first one with 2 times $5 \mathrm{~mL}$ 
of acetonitrile, recovered in a first calcined tube, and a second one with 2 times $5 \mathrm{~mL}$ of a mixture of $95 / 5$ acetonitrile and a $25 \%$ solution of ammonium hydroxide $\mathrm{NH}_{4} \mathrm{OH}$, recovered in a second calcined tube. Improved recoveries using a second elution step with $\mathrm{NH}_{4} \mathrm{OH}$ have already been demonstrated by Bergé et al. 2016 [20]. The extracts obtained after SPE were recombined and evaporated to dryness at $40^{\circ} \mathrm{C}$ under nitrogen stream and then stored at $-18^{\circ} \mathrm{C}$. Before LC-MS/MS analysis, the extract was reconstituted in $800 \mu \mathrm{L}$ of the injection solvent, which was a mixture of acetonitrile, mineral water and a $25 \% \mathrm{NH}_{4} \mathrm{OH}$ solution, $30 / 65 / 5(\mathrm{v} / \mathrm{v} / \mathrm{v})$.

\subsection{Liquid chromatography instrument and conditions}

An Agilent 1290 Infinity liquid chromatograph system (Agilent Technologies, Avondale, USA) was used for the chromatographic separation. Two LC methods were compared: one based on hydrophobic and anionic exchange interactions, referenced as RP/anion.exch and the second, only based on hydrophobic interaction. For both methods, the injection volume was $40 \mu \mathrm{L}$ and the injection solvent was a mixture of acetonitrile, water and a $25 \%$ ammonium hydroxide $\left(\mathrm{NH}_{4} \mathrm{OH}\right)$ with the respective proportions of $30 \%, 65 \%$ and $5 \%\left(25 \% \mathrm{NH}_{4} \mathrm{OH}\right.$ solution). $\mathrm{NH}_{4} \mathrm{OH}$ was added in the injection solvent to prevent the cationic surfactants from adhering to the silanol moieties of the glass tubes. The RP/anion.exch method was based on previous work [20]. The column was an Acclaim Surfactant Plus $3.0 \mu \mathrm{m}(150$ x 3) mm (Thermo Fisher Scientific, Waltham, MA, USA), the flow rate set at $900 \mu \mathrm{L} / \mathrm{min}$ and temperature oven at $30^{\circ} \mathrm{C}$, aqueous phase (A) was LC-MS grade water at $5 \mathrm{mM}$ ammonium acetate and $0.1 \%$ formic acid and organic phase (B) acetonitrile at $5 \mathrm{mM}$ ammonium acetate. In the second method, the column was a Poroshell $120 \mathrm{C} 18$ (Agilent) $1.9 \mu \mathrm{m}(50 \times 2.1) \mathrm{mm}$, the flow rate set at 500 $\mu \mathrm{L} / \mathrm{min}$ and temperature oven at $40^{\circ} \mathrm{C}$, aqueous phase (A) was LC-MS grade water at $0.1 \%$ formic acid for positive ESI and at $1 \mathrm{mM}$ ammonium acetate for negative ESI, and organic phase (B) methanol. The mobile phase gradients are summarized in Tables S3 and S4. 


\subsection{Tandem mass spectrometry instrument and parameters}

The MS/MS instrument was a 3200 QTrap (Sciex, Foster City, USA) triple quadrupole mass spectrometer, used with electrospray (ESI) ionization. To optimize MS/MS parameters, solutions at $1 \mathrm{mg} / \mathrm{L}$ of each compound in a water/methanol mixture (50/50) with $10 \mathrm{mM} \mathrm{NH}_{4} \mathrm{Ac}$ for the negative ESI and $10 \mathrm{mM} \mathrm{NH}_{4} \mathrm{Ac}$ and $0.1 \%$ formic acid for the positive ESI, were prepared and infused, one by one, at $10 \mu \mathrm{L} / \mathrm{min}$ in the mass spectrometer.

The $1^{\text {st }}$ stage of optimization consisted of determining in which ionization mode, positive or negative, the response factor of each molecule was the highest and which ion was the most abundant (parent ion) and optimize the declustering potential (DP) (Table 1).

The $2^{\text {nd }}$ stage of optimization consisted of choosing the $\mathrm{m} / \mathrm{z}$ of at least 2 fragments (product ions) that appeared the most intense, for each molecule, and optimize their collision energy (CE). The multiple reaction monitoring (MRM) mode was used to achieve the quantitative analysis of the target compounds. Two MRM transitions, parent ion $>$ product ion, were monitored for each target compound: the most sensitive one, for quantification (MRM1), and the least sensitive one for confirmation (MRM2) (Table 1). Finally, the source temperatures were also optimized and finally set to 450 and $500^{\circ} \mathrm{C}$, for negative and positive ionization modes respectively.

\subsection{Validation and application}

Spiked mineral water was employed to perform the validation of the analytical method. A loading sample volume of $400 \mathrm{~mL}$ was used for the optimized Oasis HLB SPE protocol. In the case of no contamination of method blank (i.e., signal to noise $(\mathrm{S} / \mathrm{N})$ signa $<10)$, method limits of quantification (LQ) were determined as the analyte concentration that produced a peak signal of 10 times the background noise from the chromatogram. In the opposite case (i.e., $\mathrm{S} / \mathrm{N}>10$ in method blanks), LQ were determined so that they were 2 times higher than the peak area of the 
method blank. LQ were finally validated according to the French standard NF T90-210 [21] (AFNOR 2009). Intra and inter days precisions and trueness experiments were performed using spiked mineral water at LQ and at 10 times LQ. Linearity was evaluated between LQ and 10 times LQ. To determine the trueness, 6 mineral water spiked at LQ and 6 at 10 times LQ were extracted and analyzed according to the optimized protocol, and quantified with matrixmatched calibration. The recovery percentage between the expected and the obtained concentrations was finally calculated.

River water samples $(n=36)$ were collected on French territory as part of a national campaign on emerging pollutants carried out in 2018 and 2019, called EMNAT. They were delivered to the laboratory within $24 \mathrm{hrs}$ in coolers maintained at $4^{\circ} \mathrm{C}$, and used to assess the suitability of the validated method for the characterisation of traces in surface water. Protocol was the following: after filtration with a calcined glass fiber filter, $450 \mathrm{~mL}$ of sample were transferred to a $500 \mathrm{~mL}$ glass vial, previously calcined at $450^{\circ} \mathrm{C}$ for $15 \mathrm{hrs}$. Then, after spiking the sample with $2.25 \mathrm{~mL}$ of a solution of deuterated compounds (BDDA-d5 (100 $\mu \mathrm{g} / \mathrm{L})$, HexPyr-d5 (1000 $\mu \mathrm{g} / \mathrm{L})$, SDS-d25) $(1000 \mu \mathrm{g} / \mathrm{L}))$, the optimized SPE method was performed with a loading volume of $400 \mathrm{~mL}$. Finally, the reconstituted extract was analysed by LC-MS/MS, and surfactants were quantified using matrix-matched calibration with mineral water packaged in glass bottles as the reference matrix. Extractions of the samples were performed the day of reception and analysis of the extracts were done in the month following their sampling. Between each sample, the channels of the SPE system were cleaned with $10 \mathrm{~mL}$ of methanol, then 10 $\mathrm{mL}$ of a solvent mixture (LC-MS grade water, isopropanol, acetonitrile, methanol 25/25/25/25 with $1 \%$ formic acid) and finally $10 \mathrm{~mL}$ of mineral water. Each sample was spiked with three surrogate standards, BDDA-d5, HexPyr-d5 in positive ESI and SDS-d25 in negative ESI, in order to monitor the quality of extraction and analysis. Surfactants were identified thanks to a 
$\mathrm{S} / \mathrm{N}>10$ for $\mathrm{MRM} 1, \mathrm{~S} / \mathrm{N}>3$ for MRM2 and the concordance of retention time and MRM ratio (Table 1) in the sample with those of the corresponding standard.

\section{Results and discussion}

\subsection{Liquid chromatography optimization}

The objective of this step was to find the optimal chromatographic conditions that allowed the quantification of all target compounds using a minimum of analytical methods. As the physicochemical properties of the molecules already required them to be analysed in two ionisation modes, in positive mode and in negative mode, the aim was to optimize two chromatographic methods, one for positively charged compounds and one for negatively charged compounds.

As surfactants have both hydrophobic and ionic functions, they can create both hydrophobic and ionic interactions with the stationary phases of the LC column. We choose to compare two LC methods, which involved two types of column: C18 grafted silica, which is the most commonly used phase, and a phase that combines hydrophobic interactions and anionic exchanges (RP/anion.exch), specially designed for the analysis of surfactants [20]. Figures 1 and 2 compare the chromatograms obtained with the two methods, respectively in positive and negative modes. Overall, there is a very clear difference in asymmetry and peak width. Indeed, peaks were sharper and presented a more Gaussian shape with the $\mathrm{C} 18$ column. However, the $\mathrm{RP} /$ anion exch. column provided a better resolution than the C18 column. Several parameters, which are mainly related to the size and stationary phase of the column, can explain this result. Indeed, on the one hand, the $\mathrm{C} 18$ column has a smaller internal diameter, $2.1 \mathrm{~mm}$ as opposed to $3 \mathrm{~mm}$ for the RP/anion.exch column. Smaller diameter columns are operated at lower flow rates than larger columns. This allows both a reduction in solvent consumption and also an increase in sensitivity in ESI-MS, the efficiency of ESI sources being much higher with lower 
flow rates [22]. On the other hand, two main parameters of the stationary phases explain the differences observed: the interactions involved and the particle size. The binding energies of the ionic interactions $(100-350 \mathrm{~kJ} / \mathrm{mol})$ are higher than those of the hydrophobic interactions $(5-10 \mathrm{~kJ} / \mathrm{mol})$, which may explain the tailing of the peaks obtained with the RP/anion.exch column. In addition, the particle size of the RP/anion.exch column is $3 \mu \mathrm{m}$, compared to 1.9 $\mu \mathrm{m}$ for the $\mathrm{C} 18$ column, i.e. corresponding to UHPLC conditions. This last parameter is probably the most critical since the efficiency of an LC column is inversely proportional to the particle diameter [23]. Consequently, we choose the method with the C18 column for the remainder of this study. Retention times of the targeted surfactants are presented in Table 1.

\subsection{Solid Phase Extraction optimization}

As for LC, surfactants can both create hydrophobic or ionic interactions with the phases of SPE cartridges. In this work, three types of phases were tested: the first one is a polymeric phase combining hydrophobic and hydrophilic groups, Oasis HLB, which is one of the most used SPE phase. It results from the polymerisation of two monomers: a lipophilic, divinylbenzene and a hydrophilic, N-vinylpyrrolidone (DVB-NVP) (Table S5). It presents several advantages: its benzene functions allow interactions $\pi-\pi$ with the phenyl of the surfactants and, as a polymeric phase, it has a greater load-bearing capacity and does not deteriorate during the drying steps. As C18 grafted silica phases have also been frequently selected in the literature for the extraction of surfactants, we selected Strata-C18-E, which is composed of endcapped C18 grafted silica, which allows the reduction of residual silanols. Finally, the $3^{\text {rd }}$ evaluated phase is composed of $\mathrm{C} 8$ grafted silica and aminopropyl and combines hydrophobic interactions and anionic exchanges (Cunax2). 
Figure $3 \mathrm{~A}$ shows the extraction recoveries of the anionic surfactants performed with the three types of SPE cartridges. The three families of surfactants show different trends: regarding alkylsulfates (EHS and SDS), the recoveries of the 3 cartridges were very similar, with a slight decrease, less than $10 \%$, in the case of Strata-C18-E. For LAS C10 to C13, the Cunax 2 cartridge gave the best recoveries, which is probably linked to the presence of anionic exchange sites that allow better retention of these compounds. After the Cunax 2 cartridge, the Oasis HLB provided the best recovery for LAS C10 and C11, whereas it was the Strata-C18-E for LAS C12 and C13. Lower extraction yields with the Oasis HLB for LAS C12 and C13 have also been reported by Lara-Martin [5]. This difference can be explained by the longer alkyl chain length of LAS $\mathrm{C} 12$ and $\mathrm{C} 13$, which allowed higher retention with $\mathrm{C} 18$ chains. However, the recoveries between these two cartridges remained comparable. Finally, considering laureth sulphates $\left(\mathrm{C}_{12} \mathrm{EO}_{1-2} \mathrm{~S}\right)$, Cunax2 gave the best results, followed by Oasis HLB and finally Strata-C18-E, with a 20\% loss between Strata-C18-E and Cunax2. Overall, Cunax2 showed the best recoveries for all anionic surfactants, as reported by Bergé et al. [20]. However, the Oasis HLB and Strata-C18-E cartridges also allowed good retention of these compounds since the losses observed were less than $25 \%$, which is in line with the literature.

Figure 3B show the recoveries of non-ionic surfactants obtained with the three types of SPE cartridges. Overall, as for anionic surfactants, except for TMDD, the three solid phases gave similar recoveries, with differences between the cartridges lower than $20 \%$. Slightly higher recoveries are nevertheless observed with Strata-C18-E. These observations are consistent with the study of DeArmond and DiGoregorio [17], in which DVB-NVP, C18 and C8 solid phases were compared for NPEO and OPEO extraction. Regarding TMDD, recoveries about 2 times lower were obtained with Cunax2. This may be related to the fact that TMDD does not contain a long alkyl chain, unlike other non-ionic surfactants. It is therefore likely that the C8 alkyl chain of Cunax 2 is not hydrophobic enough to retain these compounds. 
Results for cationic surfactants were much more contrasted (Figure 3C). Overall, the Oasis HLB cartridge gave the highest recoveries and Strata-C18-E the lowest ones. For BAC-C 12 , the average recovery was higher with the $\mathrm{C} 18$ phase but the repeatability was poor, as for the zwitterionic surfactant cetylbetaine. For other cationic surfactants, the recovery of Strata-C18E was significantly lower than the other two phases with almost $0 \%$ recovery for TEAQ-C 16 and SADP-DMA. The recovery obtained with Cunax2 was lower but fairly close to that obtained for Oasis HLB. As Oasis HLB is the most reported cartridge for cationic surfactant extraction [14], these observations are consistent with the literature.

In summary, the optimal cartridge was different for each type of surfactant: Cunax 2 for anionic surfactants, Strata-C18-E for non-ionic surfactants and Oasis HLB for cationic surfactants. The objective of extracting all 27 substances in a single step therefore required finding the best compromise. In our case, even if it was not optimum for LAS, it was finally the Oasis HLB SPE cartridge that globally allowed the most efficient extraction of all the targeted surfactants and therefore was selected. Finally, supplementary experiments with Oasis HLB were performed to determine if the lower recoveries of OPEO and cationic surfactants were from lack of retention or incomplete elution. These showed that the elution was incomplete but the addition of elution steps was tested and did not increase the recoveries.

\subsection{Blank contamination}

Surfactants are widely used and can be present in air, water, organic solvents or plastics. It is recognised that one of the major problems in trace analysis of micropollutants is possible contamination at every stage of the analytical procedure, from sampling and sample preparation to chromatographic analysis, which often leads to false positive or overestimated results [24]. It is sometimes impossible to eliminate this contamination but, at least, it is important to ensure 
that it is stable and to decrease it so that contamination-related concentrations are negligible compared to expected concentrations in real samples.

During the optimization of the LC-MS/MS method, we observed the presence of some of the targeted molecules in the injection solvent used to perform the instrument blanks. In order to limit this contamination, we first tested solvents and salts (acetonitrile and $\mathrm{NH}_{4} \mathrm{OH}$ ) from different suppliers, but these experiments did not allow to reduce the contamination . Then we tested different waters: water from a MilliQ filtration system, LC-MS grade water, and finally mineral water packaged in glass bottles. Figure 4 shows the signal to noise $(\mathrm{S} / \mathrm{N})$ ratios of surfactants, with $\mathrm{S} / \mathrm{N}$ greater than 10, in the instrument blanks prepared with MilliQ and mineral water. The three types of surfactants, non-ionic, anionic and cationic, presented instrument blank contamination. The use of mineral water drastically reduced contamination linked to the injection solvent, especially regarding OPEOs. LC-MS grade water gave intermediate contaminations between MilliQ water and mineral water. Even if $\mathrm{S} / \mathrm{N}$ ratios of instrument blanks were lower, they remained high for some molecules, between 15 for DDAC-C 10 and 75 for SDS. Corresponding concentrations in mineral water instrument blanks, estimated with external calibration, are presented in Table S6. While blank contaminations related to LAS and APEOs have already been referenced $[2,25]$, little or no data exist for SDS, BACs, DDACs and TEAQ.

After the impact of the injection solvent, the second source of contamination studied was the filtration step. To reduce it, calcination of the glass fibre filters can be a good solution, as reported by Loyo-Rosales et al [15]. Figure S1 shows the areas normalized to 100 of the method blanks prepared with mineral water (i.e. including the SPE step) carried out without filtration and with filtration using a filter without pre-treatment and a filter previously calcined at $450^{\circ} \mathrm{C}$ for 8 hours. For non-ionic and cationic surfactants, the calcination was relatively efficient with a decrease in peak areas between $40 \%$ for $\mathrm{BAC}-\mathrm{C}_{14}$ and $90 \%$ for $\mathrm{DDAC}-\mathrm{C}_{10}$. In addition, the 
areas of TEAQ- $\mathrm{C}_{16}$ and DDAC-C 10 in the method blanks were the same without filtration and with filter calcination. With decreases of less than $30 \%$, calcination was less effective regarding anionic surfactants. Only the TMDD contamination did not decrease. Nevertheless, thanks to the use of mineral water in the injection solvent and the filter calcination, stability of method blank contamination was obtained. Method blank concentrations were estimated based on method blank signal to noise and are reported in Table 2.

\subsection{Method validation}

Validation is an essential step of the life cycle of an analytical method [26]. It allows identifying the limits of the method, its field of application, and recovery characteristics. Performances of the method (trueness and repeatability) enable to determine the uncertainties in the measurements. We therefore thoroughly evaluated the optimised analysis method in terms of sensitivity, linearity, trueness, repeatability and intermediate precision (inter days), using mineral water packaged in glass bottles as the reference matrix (Tables 2 and 3).

Method limits of quantification (LQ) were all lower than $1 \mu \mathrm{g} / \mathrm{L}$ (Table 2). They were ranged between $15 \mathrm{ng} / \mathrm{L}$ (LAS C10) and $485 \mathrm{ng} / \mathrm{L}$ (SDS). LQ of LAS C11 and C12, $\mathrm{C}_{12} \mathrm{EO}_{1-2} \mathrm{~S}, \mathrm{SDS}$ and TEAQ were above $100 \mathrm{ng} / \mathrm{L}$ not because of a lack of sensitivity but due to residual contamination of method blanks. Although our method was multi-family and therefore required some compromises, the LQ obtained were comparable or even lower than those in the literature. Only those of the quaternary ammoniums BAC-C 12 and $\mathrm{C}_{14}$ and DDAC- $\mathrm{C}_{10}$ were higher than those of the work of Ostman et al. [14] but the method developed in this article was specific to cationic surfactants. Absolute extraction recoveries, evaluated at five times LQ, were above $75 \%$ for anionic surfactants and between 56 and $78 \%$ for non-ionic surfactants (Table 2). They were lower for cationic surfactants, between 36 and 56\%, and more particularly for TEAQ with 
recoveries comprised between 36 and $38 \%$. This could be explained by the both cationic and hydrophobic nature of TEAQ which may not be fully eluted from SPE cartridges.

In order to take into account contamination brought by the analytical protocol and the lowest recoveries, matrix-matched calibration was chosen using mineral water packaged in glass bottles as the reference matrix. Linearity range and determination coefficients obtained with this strategy are presented in Table 3. All determination coefficients were more than 0.99 . In addition, for each analyte, the deviation of back calculated concentration from true concentration, using the calibration curve, was monitored for each calibration point and was always inferior to 20\%. Trueness was evaluated at the LQ and at ten times LQ levels (see section 2.5). In both cases, trueness was above $80 \%$, showing that matrix-matched calibration was effective in correcting for lower cationic surfactant recoveries. Repeatability and intermediate precision over 3 days were also assessed at these two concentration levels. The coefficients of variation $(\mathrm{CV})$ were between 8 and $25 \%$ and between 4 and $29 \%$ for repeatability and intermediate precision respectively. TEAQ were the compounds with the most variability, for two possible reasons: high and variable levels of blank contamination and low response factors in mass spectrometry. Overall, these validation data were satisfactory, and the method was validated.

\subsection{Application to field samples}

The validated analytical method was applied to 36 river water samples, collected throughout France in 2018. The surfactants were quantified using a matrix-matched calibration with the standards being spiked mineral water (packaged in doped glass bottles) that had undergone the entire analytical protocol. Twelve method blanks were extracted along with the samples and injected in the same LC-MS/MS sequences to ensure that the signals of the substances in the blanks were below the corresponding LQ. The MRM of the surrogate standards were monitored 
at each injection and the coefficients of variation of their areas in field samples were 18, 25 and $27 \%$ respectively for BDDA-d5, HexPyr-d5 and SDS-d25. These areas were compared to those of the calibration standards and method blanks to monitor the quality of extraction and analysis in real samples. This comparison showed a signal suppression for BDDA-d5 and a signal increase for HexPyr-d5 and SDS-d25. However, these matrix effects were less than $25 \%$, and were therefore still acceptable.

The number of positive samples, quantification frequencies and median concentrations of the targeted surfactants are summarised in Table 4. Anionic (LAS, AES, AS), cationic (DDAC-C 10 and LaurPyr) and non-ionic $\left(\mathrm{OP}_{7-11} \mathrm{EO}, \mathrm{TMDD}\right)$ surfactants were quantified. Eight substances were never quantified, comprising mainly cationic surfactants and the zwitterionic surfactant cetylbetaine. This is consistent with the literature which shows that cationic surfactants are predominantly present in the particular phase of environmental matrices [27]. The non-ionic surfactants OPEOs and CMEA were quantified in less than 5\% of the samples. On the other hand, TMDD was quantified in $25 \%$ of the samples with a median concentration of $347 \mathrm{ng} / \mathrm{L}$. This compound has so far been investigated in only 2 studies [18, 28], and reported at mean concentrations of about $500 \mathrm{ng} / \mathrm{L}$, which is in accordance with our study. Finally, anionic surfactants were the most frequently quantified, and at the highest concentrations, especially LAS. Indeed, the frequencies of quantification of LAS-C10 to C13 were greater than $90 \%$, and their median concentrations were between 0.71 and $4.6 \mu \mathrm{g} / \mathrm{L}$. This finding is coherent with previous monitoring in Spain [10] and Malaysia [11]. Although LAS are well eliminated by WWTP, the concentrations in the effluents are still significant, leading to pseudo-persistence in the environment $[29,30]$. These results therefore show that the analytical method developed is well suited to the analysis of surfactants in surface waters. 


\section{Conclusion}

An offline SPE LC-MS/MS was successfully developed for the analysis of anionic, non-ionic and cationic surfactants, with only one extraction and two LC injections. This last point could be further improved by using only one separation with polarity switching. As these compounds have many areas of application and are used in high tonnages, contaminations of instrument and method blanks were investigated and taken into account for the determination of LQ. Nevertheless, analytical recoveries were adequate for the analysis of surfactants in river water, with LQ between 15 and $485 \mathrm{ng} / \mathrm{L}$. The application of this method on samples collected in France showed a strong presence of anionic surfactants, especially LAS. The analytical method developed in this work will therefore be useful for future monitoring of surfactants. Moreover, this method, which shows good recoveries for anionic, non-ionic and cationic surfactants, may be easily adapted to other surfactants.

\section{Acknowledgments}

The authors thank the French Biodiversity Agency for the financial support of the whole EMNAT 2018 campaign. This work was performed within the framework of the EUR H2O'Lyon (ANR-17-EURE-0018) of Université de Lyon (UdL), within the program "Investissements d'Avenir" operated by the French National Research Agency (ANR). The authors thank also Robert Baudot and Maëva Fieu for their great contribution in surfactant analysis. 


\section{References}

[1] ECHA (2019): "Universe of registered substances" https://echa.europa.eu/fr/universe-ofregistered-substances (accessed 1 March 2021)

[2] Li, W. L., Zhang, Z. F., Sparhamb, C. and Li, Y. F. Validation of sampling techniques and SPEUPLC/MS/MS for home and personal care chemicals in the Songhua Catchment, Northeast China. Science of the Total Environment. 707 (2020) 136038.

[3] Margot, J., Rossi, L., Barry, D. A. and Holliger, C. A review of the fate of micropollutants in wastewater treatment plants. Wiley Interdisciplinary Reviews-Water. 2 (2015) 457-487.

[4] Freeling, F., Alygizakis, N. A., von der Ohe, P. C., Slobodnik, J., Oswald, P., Aalizadeh, R., Cirka, L., Thomaidis, N. S. and Scheurer, M. Occurrence and potential environmental risk of surfactants and their transformation products discharged by wastewater treatment plants. Science of the Total Environment. 681 (2019) 475-487.

[5] Lara-Martin, P. A., Gonzalez-Mazo, E. and Brownawell, B. J. Multi-residue method for the analysis of synthetic surfactants and their degradation metabolites in aquatic systems by liquid chromatography-time-of-flight-mass spectrometry. Journal of Chromatography A. 1218 (2011) 47994807.

[6] Huber, S., Remberger, M., Kaj, L., Schlabach, M., Jorundsdottir, H. O., Vester, J., Arnorsson, M., Mortensen, I., Schwartson, R. and Dam, M. A first screening and risk assessment of pharmaceuticals and additives in personal care products in waste water, sludge, recipient water and sediment from Faroe Islands, Iceland and Greenland. Science of the Total Environment. 562 (2016) 13-25.

[7] Barber, L. B., Loyo-Rosales, J. E., Rice, C. P., Minarik, T. A. and Oskouie, A. K. Endocrine disrupting alkylphenolic chemicals and other contaminants in wastewater treatment plant effluents, urban streams, and fish in the Great Lakes and Upper Mississippi River Regions. Science of the Total Environment. 517 (2015) 195-206.

[8] Martinez-Carballo, E., Sitka, A., Gonzalez-Barreiro, C., Kreuzinger, N., Fuerhacker, M., Scharf, S. and Gans, O. Determination of selected quaternary ammonium compounds by liquid chromatography with mass spectrometry. Part I. Application to surface,) waste and indirect discharge water samples in Austria. Environmental Pollution. 145 (2007) 489-496.

[9] Kurrey, R., Mahilang, M., Deb, M. K. and Shrivas, K. Analytical approach on surface active agents in the environment and challenges. Trends in Environmental Analytical Chemistry. 21 (2019). doi: 10.1016/j.teac.2019.e00061.

[10] Traverso-Soto, J. M., Lara-Martin, P. A., Gonzalez-Mazo, E. and Leon, V. M. Distribution of anionic and nonionic surfactants in a sewage-impacted Mediterranean coastal lagoon: Inputs and seasonal variations. Science of the Total Environment. 503 (2015) 87-96.

[11] Sakai, N., Shirasaka, J., Matsui, Y., Ramli, M. R., Yoshida, K., Mohd, M. A. and Yoneda, M. Occurrence, fate and environmental risk of linear alkylbenzene sulfonate in the Langat and Selangor River basins, Malaysia. Chemosphere. 172 (2017) 234-241.

[12] McDonough, K., Casteel, K., Itrich, N., Menzies, J., Belanger, S., Wehmeyer, K. and Federle, T. Evaluation of anionic surfactant concentrations in US effluents and probabilistic determination of their combined ecological risk in mixing zones. Science of the Total Environment. 572 (2016) 434-441.

[13] Santos, I. C., Guo, H. Y., Mesquita, R. B. R., Rangel, A., Armstrong, D. W. and Schug, K. A. Paired-ion electrospray ionization - triple quadrupole tandem mass spectrometry for quantification of anionic surfactants in waters. Talanta. 143 (2015) 320-327. 
[14] Ostman, M., Lindberg, R. H., Fick, J., Bjorn, E. and Tysklind, M. Screening of biocides, metals and antibiotics in Swedish sewage sludge and wastewater. Water Research. 115 (2017) 318-328.

[15] Loyo-Rosales, J. E., Schmitz-Afonso, I., Rice, C. P. and Torrents, A. Analysis of octyl- and nonylphenol and their ethoxylates in water and sediments by liquid chromatography/tandem mass spectrometry. Analytical Chemistry. 75 (2003) 4811-4817.

[16] Ciofi, L., Ancillotti, C., Chiuminatto, U., Fibbi, D., Pasquini, B., Bruzzoniti, M. C., Rivoira, L. and Del Bubba, M. Fully automated on-line solid phase extraction coupled to liquid chromatographytandem mass spectrometry for the simultaneous analysis of alkylphenol polyethoxylates and their carboxylic and phenolic metabolites in wastewater samples. Analytical and Bioanalytical Chemistry. 408 (2016) 3331-3347.

[17] DeArmond, P. D. and DiGoregorio, A. L. Rapid liquid chromatography-tandem mass spectrometry-based method for the analysis of alcohol ethoxylates and alkylphenol ethoxylates in environmental samples. Journal of Chromatography A. 1305 (2013) 154-163.

[18] Guedez, A. A., Froemmel, S., Diehl, P. and Puettmann, W. Occurrence and temporal variations of TMDD in the river Rhine, Germany. Environmental Science and Pollution Research. 17 (2010) 321-330.

[19] Gomez, V., Ferreres, L., Pocurull, E. and Borrull, F. Determination of non-ionic and anionic surfactants in environmental water matrices. Talanta. 84 (2011) 859-866.

[20] Berge, A., Giroud, B., Wiest, L., Domenjoud, B., Gonzalez-Ospina, A. and Vulliet, E. Development of a multiple-class analytical method based on the use of synthetic matrices for the simultaneous determination of commonly used commercial surfactants in wastewater by liquid chromatography-tandem mass spectrometry. Journal of Chromatography A. 1450 (2016) 64-75.

[21] AFNOR 2009 NF T90-210 - Water quality - Protocol for the initial method performance assessment in a laboratory - May 2009 - AFNOR, 2009.

[22] Alcantara-Duran, J., Moreno-Gonzalez, D., Gilbert-Lopez, B., Molina-Diaz, A. and GarciaReyes, J. F. Matrix-effect free multi-residue analysis of veterinary drugs in food samples of animal origin by nanoflow liquid chromatography high resolution mass spectrometry. Food Chemistry. 245 (2018) 29-38.

[23] Kormany, R., Tamas, K., Guillarme, D. and Fekete, S. A workflow for column interchangeability in liquid chromatography using modeling software and quality-by-design principles. Journal of Pharmaceutical and Biomedical Analysis. 146 (2017) 220-225.

[24] Szczepanska, N., Rutkowska, M., Owczarek, K., Plotka-Wasylka, J. and Namiesnik, J. Main complications connected with detection, identification and determination of trace organic constituents in complex matrix samples. Trac-Trends in Analytical Chemistry. 105 (2018) 173-184.

[25] Salgueiro-Gonzalez, N., Concha-Grana, E., Turnes-Carou, I., Muniategui-Lorenzo, S., LopezMahia, P. and Prada-Rodriguez, D. Blank and sample handling troubleshooting in ultratrace analysis of alkylphenols and bisphenol A by liquid chromatography tandem mass spectrometry. Talanta. 101 (2012) 413-419.

[26] Rambla-Alegre, M., Esteve-Romero, J. and Carda-Broch, S. Is it really necessary to validate an analytical method or not? That is the question. Journal of Chromatography A. 1232 (2012). 101-109. [27] Martinez-Carballo, E., Gonzalez-Barreiro, C., Sitka, A., Kreuzinger, N., Scharf, S. and Gans, O. Determination of selected quaternary ammonium compounds by liquid chromatography with mass spectrometry. Part II. Application to sediment and sludge samples in Austria. Environmental Pollution. 146 (2007) 543-547. 
[28] Dsikowitzky, L., Botalova, O., Illgut, S., Bosowski, S. and Schwarzbauer, J. Identification of characteristic organic contaminants in wastewaters from modern paper production sites and subsequent tracing in a river. Journal of Hazardous Materials. 300 (2015) 254-262.

[29] Matthies, M., Solomon, K., Vighi, M., Gilman, A. and Tarazona, J. V. The origin and evolution of assessment criteria for persistent, bioaccumulative and toxic (PBT) chemicals and persistent organic pollutants (POPs). Environmental Science-Processes \& Impacts. 18 (2016, 1114-1128.

[30] Cowan-Ellsberry, C., Belanger, S., Dorn, P., Dyer, S., McAvoy, D., Sanderson, H., Versteeg, D., Ferrer, D. and Stanton, K. Environmental Safety of the Use of Major Surfactant Classes in North America. Critical Reviews in Environmental Science and Technology. 44 (2014) 1893-1993. 




Figure 1: Chromatograms in positive ESI with columns (A) RP/anion.exch and (B) C18. 


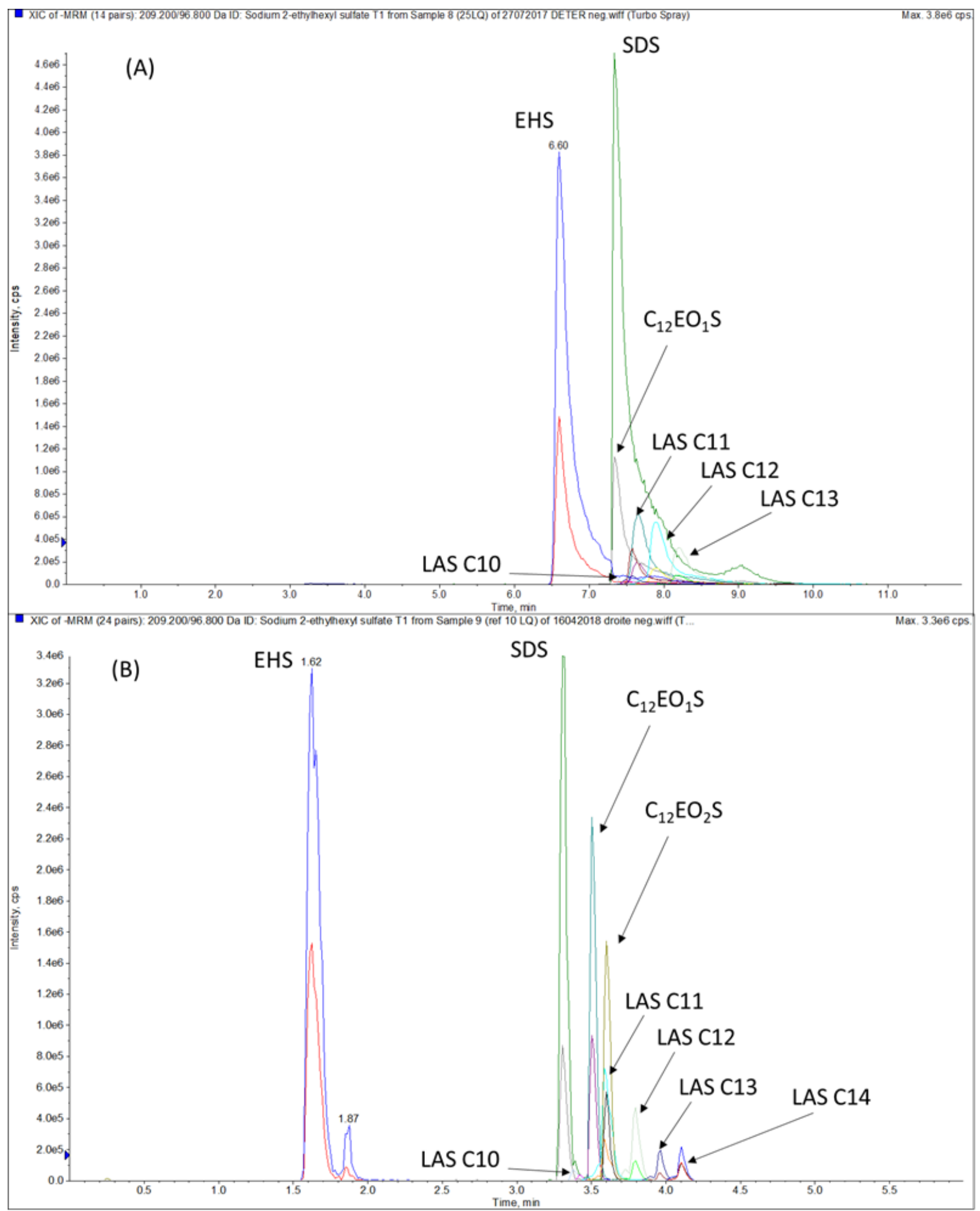

Figure 2: Chromatograms in negative ESI with columns (A) RP/anion.exch and (B) C18 

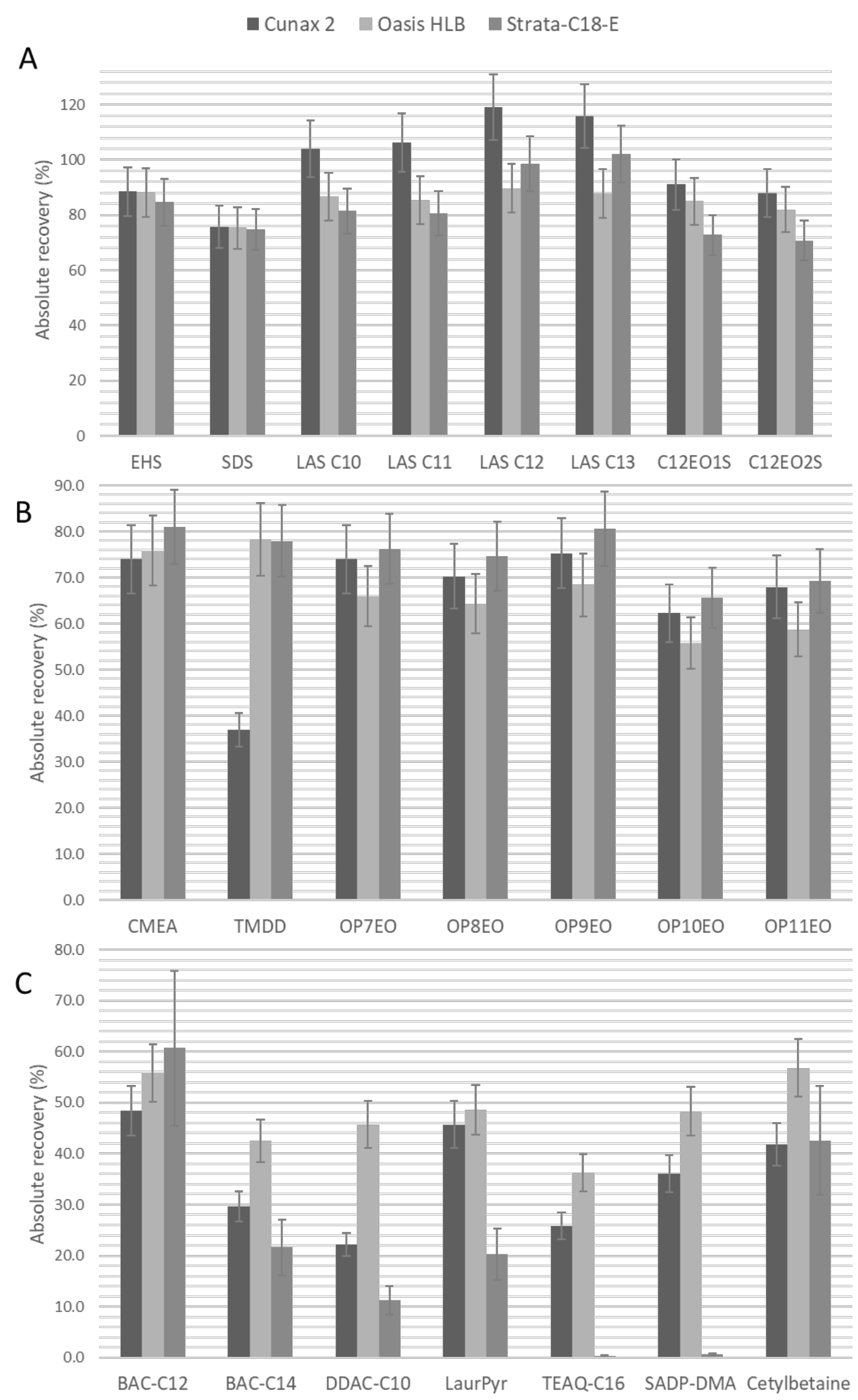

Figure 3: Absolute extraction recoveries for three SPE cartridges for (A) Anionic, (B) non-ionic and (C) cationic surfactants $(\mathrm{n}=3)$ 


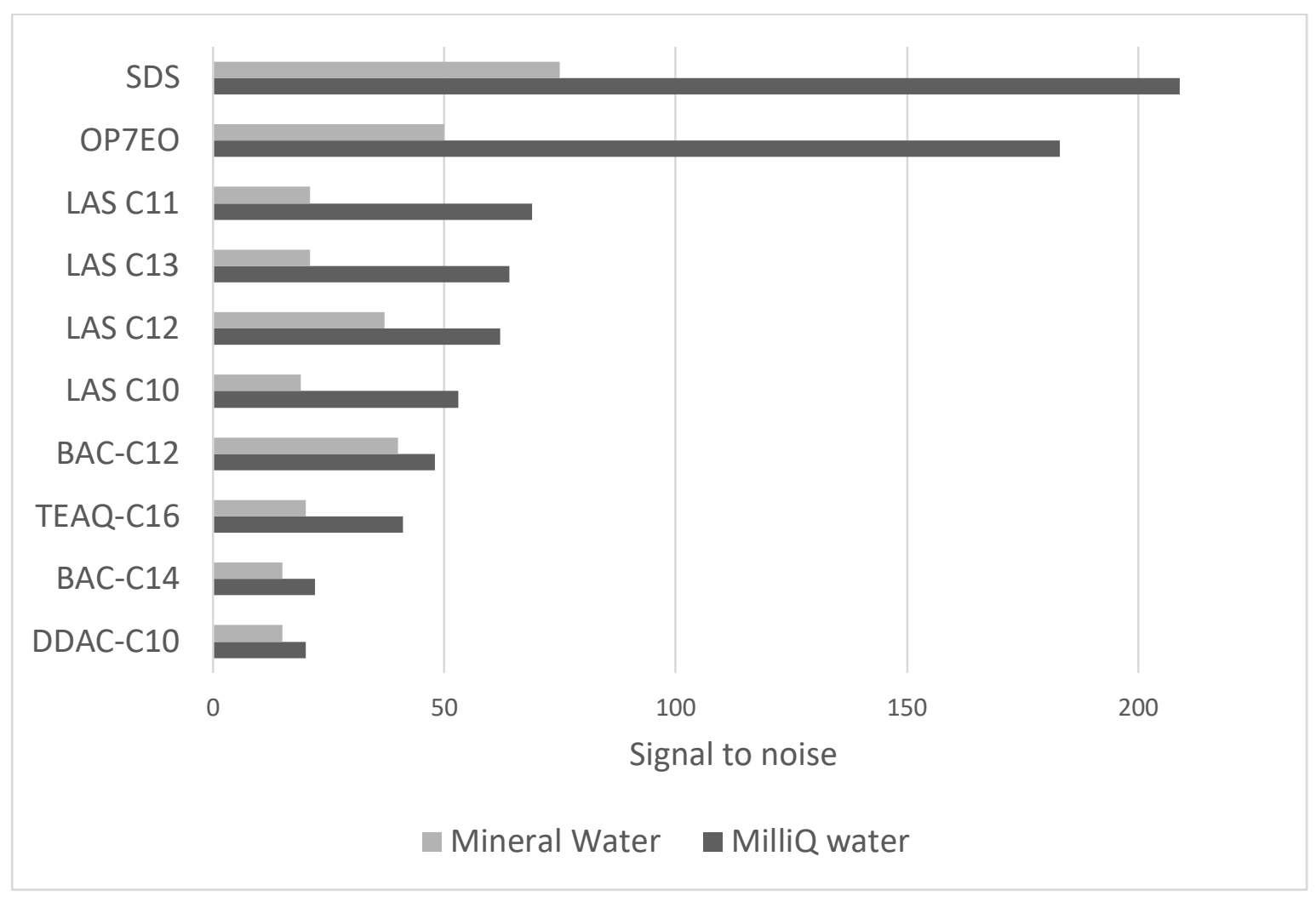

Figure 4: Signal to noise ratios of instrument blanks prepared with mineral and MilliQ water (substances with $\mathrm{S} / \mathrm{N}$ greater than 10 in instrument blanks) 
Table 1: Formula, retention times $\left(t_{R}\right)$ and MS/MS parameters of the targeted surfactants

\begin{tabular}{|c|c|c|c|c|c|c|c|c|c|c|}
\hline Name & Formula & $\begin{array}{c}t_{R} \\
(\min )\end{array}$ & $\begin{array}{l}\text { Parent } \\
\text { Ion } \\
(\mathrm{m} / \mathrm{z})\end{array}$ & $\begin{array}{c}\text { Ion } \\
\text { formed }\end{array}$ & $\begin{array}{l}\text { DP } \\
\text { (V) }\end{array}$ & $\begin{array}{c}\text { Product } \\
\text { Ion 1 } \\
(\mathrm{m} / \mathrm{z})\end{array}$ & $\begin{array}{l}\text { CE } \\
\text { (V) }\end{array}$ & $\begin{array}{c}\text { Product } \\
\text { Ion } 2 \\
(\mathrm{~m} / \mathrm{z})\end{array}$ & $\begin{array}{l}\text { CE } \\
\text { (V) }\end{array}$ & $\begin{array}{r}\text { MRM } \\
\text { ratio }\end{array}$ \\
\hline \multicolumn{11}{|l|}{ Negative ESI } \\
\hline LAS C10 & $\mathrm{C}_{16} \mathrm{H}_{25} \mathrm{O}_{3} \mathrm{~S}$ & 3.35 & 297 & {$\left[\mathrm{M}^{-}\right.$} & -75 & 119 & -62 & 183 & -38 & 2.43 \\
\hline LAS C 11 & $\mathrm{C}_{17} \mathrm{H}_{27} \mathrm{O}_{3} \mathrm{~S}$ & 3.57 & 311 & {$\left[\mathrm{M}^{-}\right.$} & -80 & 183 & -48 & 119 & -68 & 3.22 \\
\hline LAS C12 & $\mathrm{C}_{18} \mathrm{H}_{29} \mathrm{O}_{3} \mathrm{~S}$ & 3.77 & 325 & {$[\mathrm{M}]^{-}$} & -85 & 183 & -48 & 119 & -70 & 3.81 \\
\hline LAS C13 & $\mathrm{C}_{19} \mathrm{H}_{31} \mathrm{O}_{3} \mathrm{~S}$ & 3.94 & 339 & {$[\mathrm{M}]^{-}$} & -95 & 183 & -50 & 119 & -72 & 4.04 \\
\hline LAS C14 & $\mathrm{C}_{20} \mathrm{H}_{33} \mathrm{O}_{3} \mathrm{~S}$ & 4.09 & 353 & {$[\mathrm{M}]^{-}$} & -70 & 183 & -50 & 119 & -76 & 5.37 \\
\hline $\mathrm{C}_{12} \mathrm{EO}_{1} \mathrm{~S}$ & $\mathrm{C}_{14} \mathrm{H}_{29} \mathrm{O}_{5} \mathrm{~S}$ & 3.49 & 309 & {$[\mathrm{M}]^{-}$} & -60 & 97 & -44 & 80 & -78 & 0.97 \\
\hline $\mathrm{C}_{12} \mathrm{EO}_{2} \mathrm{~S}$ & $\mathrm{C}_{16} \mathrm{H}_{33} \mathrm{O}_{6} \mathrm{~S}$ & 3.58 & 353 & {$[\mathrm{M}]^{-}$} & -65 & 97 & -48 & 80 & -88 & 3.34 \\
\hline SDS & $\mathrm{C}_{12} \mathrm{H}_{25} \mathrm{O}_{4} \mathrm{~S}$ & 3.29 & 265 & {$[\mathrm{M}]^{-}$} & -65 & 97 & -36 & 80 & -82 & 6.30 \\
\hline EHS & $\mathrm{C}_{8} \mathrm{H}_{17} \mathrm{O}_{4} \mathrm{~S}$ & 1.60 & 209 & {$[\mathrm{M}]^{-}$} & -55 & 97 & -32 & 80 & -60 & 3.37 \\
\hline \multicolumn{11}{|l|}{ Positive ESI } \\
\hline $\mathrm{OP}_{7} \mathrm{EO}$ & $\mathrm{C}_{28} \mathrm{H}_{50} \mathrm{O}_{8}$ & 3.87 & 532 & {$\left[\mathrm{M}+\mathrm{NH}_{4}\right]^{+}$} & 46 & 89 & 41 & 133 & 33 & 1.19 \\
\hline $\mathrm{OP}_{8} \mathrm{EO}$ & $\mathrm{C}_{30} \mathrm{H}_{54} \mathrm{O}_{9}$ & 3.90 & 576 & {$\left[\mathrm{M}+\mathrm{NH}_{4}\right]^{+}$} & 51 & 89 & 47 & 133 & 33 & 1.40 \\
\hline $\mathrm{OP}_{9} \mathrm{EO}$ & $\mathrm{C}_{32} \mathrm{H}_{58} \mathrm{O}_{10}$ & 3.92 & 620 & {$\left[\mathrm{M}+\mathrm{NH}_{4}\right]^{+}$} & 61 & 89 & 51 & 133 & 37 & 1.51 \\
\hline $\mathrm{OP}_{10} \mathrm{EO}$ & $\mathrm{C}_{34} \mathrm{H}_{62} \mathrm{O}_{11}$ & 3.93 & 664 & {$\left[\mathrm{M}+\mathrm{NH}_{4}\right]^{+}$} & 61 & 89 & 51 & 133 & 37 & 1.42 \\
\hline $\mathrm{OP}_{11} \mathrm{EO}$ & $\mathrm{C}_{36} \mathrm{H}_{66} \mathrm{O}_{12}$ & 3.95 & 708 & {$\left[\mathrm{M}+\mathrm{NH}_{4}\right]^{+}$} & 66 & 89 & 51 & 133 & 41 & 1.77 \\
\hline CMEA & $\mathrm{C}_{14} \mathrm{H}_{29} \mathrm{NO}_{2}$ & 3.21 & 244 & {$[\mathrm{M}+\mathrm{H}]^{+}$} & 31 & 62 & 35 & 57 & 35 & 2.22 \\
\hline TMDD & $\mathrm{C}_{14} \mathrm{H}_{26} \mathrm{O}_{2}$ & 2.58 & 369 & {$\left[\mathrm{M}+\mathrm{NH}_{4}\right]^{+}$} & 46 & 324 & 31 & 57 & 57 & 2.99 \\
\hline $\mathrm{BAC}-\mathrm{C}_{12}$ & $\mathrm{C}_{21} \mathrm{H}_{38} \mathrm{~N}$ & 2.78 & 244 & {$[\mathrm{M}]^{+}$} & 11 & 191 & 11 & 153 & 11 & 3.45 \\
\hline BAC- $\mathrm{C}_{14}$ & $\mathrm{C}_{23} \mathrm{H}_{42} \mathrm{~N}$ & 3.40 & 304 & {$[\mathrm{M}]^{+}$} & 51 & 91 & 45 & 212 & 27 & 3.34 \\
\hline BAC- $\mathrm{C}_{16}$ & $\mathrm{C}_{25} \mathrm{H}_{46} \mathrm{~N}$ & 3.88 & 332 & {$[\mathrm{M}]^{+}$} & 46 & 91 & 49 & 240 & 29 & 4.34 \\
\hline BAC- $\mathrm{C}_{18}$ & $\mathrm{C}_{27} \mathrm{H}_{50} \mathrm{~N}$ & 4.33 & 360 & {$[\mathrm{M}]^{+}$} & 86 & 268 & 31 & 91 & 59 & 2.69 \\
\hline DDAC-C 10 & $\mathrm{C}_{22} \mathrm{H}_{48} \mathrm{~N}$ & 3.62 & 388 & {$[\mathrm{M}]^{+}$} & 56 & 91 & 53 & 58 & 65 & 16.6 \\
\hline LaurPyr & $\mathrm{C}_{17} \mathrm{H}_{30} \mathrm{~N}$ & 2.25 & 326 & {$[\mathrm{M}]^{+}$} & 20 & 186 & 186 & 57 & 55 & 5.78 \\
\hline TEAQ-C $_{16}$ & $\mathrm{C}_{23} \mathrm{H}_{48} \mathrm{NO}_{4}$ & 3.80 & 248 & {$[\mathrm{M}]^{+}$} & 66 & 80 & 33 & 57 & 37 & 12.0 \\
\hline TEAQ-C $_{18}$ & $\mathrm{C}_{25} \mathrm{H}_{50} \mathrm{NO}_{4}$ & 3.93 & 402 & {$[\mathrm{M}]^{+}$} & 56 & 283 & 31 & 57 & 65 & 5.24 \\
\hline TEAQ-C ${ }_{18}$ sat. & $\mathrm{C}_{25} \mathrm{H}_{52} \mathrm{NO}_{4}$ & 4.26 & 428 & {$[\mathrm{M}]^{+}$} & 36 & 309 & 29 & 55 & 65 & 6.85 \\
\hline SADP-DMA & $\mathrm{C}_{23} \mathrm{H}_{48} \mathrm{~N}_{2} \mathrm{O}$ & 4.36 & 430 & {$[\mathrm{M}+\mathrm{H}]^{+}$} & 46 & 311 & 35 & 57 & 73 & 10.8 \\
\hline Cetylbetaine & $\mathrm{C}_{20} \mathrm{H}_{41} \mathrm{NO}_{2}$ & 4.21 & 328 & {$[\mathrm{M}+\mathrm{H}]^{+}$} & 66 & 104 & 31 & 85 & 35 & 11.8 \\
\hline
\end{tabular}

TEAQ-C 18 sat. : saturated TEAQ-C 18 
Table 2: Method limits of quantification (LQ) compared to the literature, estimated method blank concentration and absolute extraction recoveries

\begin{tabular}{|c|c|c|c|c|c|}
\hline Substance & $\begin{array}{c}\text { Method } \\
\text { LQ } \\
(\mu \mathrm{g} / \mathrm{L})\end{array}$ & $\begin{array}{c}\text { Literature } \\
\mathrm{LQ} \\
(\mu \mathrm{g} / \mathrm{L})\end{array}$ & Ref. & $\begin{array}{l}\text { Method blank } \\
\text { concentration } \\
(\mu \mathrm{g} / \mathrm{L})\end{array}$ & $\begin{array}{c}\text { Absolute } \\
\text { extraction recovery } \\
(\%) \text { at } 5 * \text { LQ }\end{array}$ \\
\hline LAS C10 & 0.015 & 1.6 & [4] & 0.005 & 86.7 \\
\hline LAS C11 & 0.113 & 1.6 & {$[4]$} & 0.015 & 85.4 \\
\hline LAS C12 & 0.101 & 1.6 & {$[4]$} & 0.01 & 89.7 \\
\hline LAS C 13 & 0.072 & 1.6 & {$[4]$} & 0.005 & 87.8 \\
\hline LAS C14 & 0.12 & 1.6 & {$[4]$} & $\mathrm{S} / \mathrm{N}<10$ & 78.2 \\
\hline $\mathrm{C}_{12} \mathrm{EO}_{1} \mathrm{~S}$ & 0.43 & 0.1 & {$[4]$} & 0.143 & 85.0 \\
\hline $\mathrm{C}_{12} \mathrm{EO}_{2} \mathrm{~S}$ & 0.34 & 0.1 & {$[4]$} & 0.113 & 82.0 \\
\hline SDS & 0.485 & 0.5 & [13] & 0.162 & 75.3 \\
\hline EHS & 0.05 & 0.5 & [13] & 0.002 & 88.2 \\
\hline $\mathrm{OP}_{7} \mathrm{EO}$ & 0.02 & 0.05 & {$[17]$} & 0.0016 & 66.0 \\
\hline $\mathrm{OP}_{8} \mathrm{EO}$ & 0.02 & 0.05 & {$[17]$} & 0.0016 & 64.3 \\
\hline $\mathrm{OP}_{9} \mathrm{EO}$ & 0.02 & 0.05 & {$[17]$} & 0.0016 & 68.4 \\
\hline $\mathrm{OP}_{10} \mathrm{EO}$ & 0.02 & 0.05 & {$[17]$} & 0.0016 & 55.8 \\
\hline $\mathrm{OP}_{11} \mathrm{EO}$ & 0.02 & 0.05 & {$[17]$} & 0.0016 & 58.7 \\
\hline CMEA & 0.1 & 0.1 & {$[20]$} & $\mathrm{S} / \mathrm{N}<10$ & 75.8 \\
\hline TMDD & 0.1 & 0.03 & {$[18]$} & 0.01 & 78.3 \\
\hline $\mathrm{BAC}-\mathrm{C}_{12}$ & 0.06 & 0.01 & {$[14]$} & 0.006 & 55.8 \\
\hline BAC- $\mathrm{C}_{14}$ & 0.04 & 0.01 & {$[14]$} & 0.01 & 42.5 \\
\hline DDAC-C 10 & 0.05 & 0.005 & {$[14]$} & 0.01 & 45.7 \\
\hline LaurPyr & 0.03 & ND & & $\mathrm{S} / \mathrm{N}<10$ & 48.6 \\
\hline TEAQ-C16 & 0.28 & 5.0 & {$[20]$} & 0.016 & 36.2 \\
\hline TEAQ-C 18 & 0.152 & ND & & 0.007 & 38.0 \\
\hline TEAQ-C 18 sat. & 0.06 & ND & & 0.016 & 35.5 \\
\hline SADP-DMA & 0.05 & 0.2 & {$[20]$} & $\mathrm{S} / \mathrm{N}<10$ & 48.3 \\
\hline Cetylbetaine & 0.1 & 0.1 & {$[20]$} & $\mathrm{S} / \mathrm{N}<10$ & 56.8 \\
\hline
\end{tabular}

TEAQ-C 18 sat. : saturated TEAQ-C 18

ND: No Data 
Table 3: Linearity range and their determination coefficient (R2), trueness, and intra and inter-days precision

\begin{tabular}{|c|c|c|c|c|c|c|c|c|}
\hline Substance & $\begin{array}{l}\text { Linearity } \\
\text { range } \\
(\mu \mathrm{g} / \mathrm{L})\end{array}$ & $\mathrm{R}^{2}$ & $\begin{array}{c}\text { Trueness (\%) } \\
\text { at LQ } \\
(\mathrm{n}=6)\end{array}$ & $\begin{array}{c}\text { Intra-day } \\
\text { precision } \\
\text { CV (\%) } \\
\text { at LQ } \\
(\mathrm{n}=6)\end{array}$ & $\begin{array}{c}\text { Inter-day } \\
\text { precision } \\
\text { CV }(\%) \text { at } \\
\text { LQ } \\
(3 \text { days }) \\
(\mathrm{n}=6)\end{array}$ & $\begin{array}{l}\text { Trueness (\%) } \\
\text { at } 10 * \text { LQ } \\
(\mathrm{n}=6)\end{array}$ & $\begin{array}{c}\text { Intra-day } \\
\text { precision } \\
\mathrm{CV}(\%) \text { at } \\
10^{*} \mathrm{LQ} \\
(\mathrm{n}=6)\end{array}$ & $\begin{array}{c}\text { Inter-day } \\
\text { precision } \\
\text { CV }(\%) \\
\text { at } 10^{*} \mathrm{LQ} \\
(3 \text { days }) \\
(\mathrm{n}=6)\end{array}$ \\
\hline LAS C10 & $0.015-0.15$ & 0.998 & 103 & 15 & 18 & 113 & 9.8 & 8.3 \\
\hline LAS C11 & $0.113-1.13$ & 0.999 & 97 & 12 & 31 & 116 & 8.4 & 7.0 \\
\hline LAS C12 & $0.101-1.01$ & 0.997 & 117 & 16 & 14 & 103 & 8.6 & 9.7 \\
\hline LAS C13 & $0.072-0.72$ & 0.990 & 98 & 8 & 17 & 86 & 15 & 17 \\
\hline LAS C14 & $0.12-1.2$ & 0.990 & 101 & 10 & 28 & 120 & 9.6 & 11 \\
\hline $\mathrm{C}_{12} \mathrm{EO}_{1} \mathrm{~S}$ & $0.43-4.3$ & 0.990 & 113 & 15 & 20 & 117 & 2.8 & 4.1 \\
\hline $\mathrm{C}_{12} \mathrm{EO}_{2} \mathrm{~S}$ & $0.34-3.4$ & 0.990 & 85 & 18 & 20 & 81 & 3.6 & 4.3 \\
\hline SDS & $0.485-4.85$ & 0.990 & 114 & 20 & 26 & 80 & 3.6 & 7.6 \\
\hline EHS & $0.05-0.5$ & 0.996 & 107 & 19 & 26 & 96 & 2.7 & 2.8 \\
\hline $\mathrm{OP}_{7} \mathrm{EO}$ & $0.02-0.2$ & 0.995 & 106 & 15 & 18 & 107 & 5.7 & 5.3 \\
\hline $\mathrm{OP}_{8} \mathrm{EO}$ & $0.02-0.2$ & 0.995 & 115 & 13 & 22 & 103 & 8.2 & 6.8 \\
\hline $\mathrm{OP}_{9} \mathrm{EO}$ & $0.02-0.2$ & 0.995 & 113 & 12 & 20 & 115 & 7.3 & 5.6 \\
\hline $\mathrm{OP}_{10} \mathrm{EO}$ & $0.02-0.2$ & 0.993 & 120 & 12 & 21 & 110 & 7.3 & 6.2 \\
\hline $\mathrm{OP}_{11} \mathrm{EO}$ & $0.02-0.2$ & 0.996 & 120 & 12 & 21 & 88 & 7.7 & 6.9 \\
\hline CMEA & $0.1-1.0$ & 0.999 & 120 & 10 & 15 & 110 & 4.1 & 5.1 \\
\hline TMDD & $0.1-0.6$ & 0.998 & 103 & 12 & 18 & 115 & 4.5 & 17 \\
\hline BAC-C 12 & $0.06-0.3$ & 0.993 & 98 & 16 & 25 & 119 & 3.2 & 5.2 \\
\hline BAC-C ${ }_{14}$ & $0.04-0.4$ & 0.994 & 88 & 17 & 25 & 111 & 3.2 & 7.0 \\
\hline DDAC-C 10 & $0.05-0.5$ & 0.990 & 112 & 12 & 28 & 109 & 5.0 & 14 \\
\hline LaurPyr & $0.03-0.3$ & 0.993 & 92 & 11 & 27 & 109 & 2.3 & 2.8 \\
\hline TEAQ-C 16 & $0.28-1.4$ & 0.993 & 92 & 15 & 15 & 87 & 22 & 27 \\
\hline TEAQ-C 18 & $0.152-0.76$ & 0.997 & 109 & 20 & 16 & 84 & 25 & 28 \\
\hline TEAQ-C $18 \mathrm{~s}$ & $0.06-0.3$ & 0.990 & 103 & 18 & 23 & 82 & 17 & 29 \\
\hline SADP-DMA & $0.05-0.25$ & 0.991 & 99 & 14 & 21 & 115 & 21 & 26 \\
\hline Cetylbetaine & $0.1-1$ & 0.999 & 105 & 10 & 18 & 101 & 4.9 & 6.0 \\
\hline
\end{tabular}

TEAQ-C 18 s: saturated TEAQ-C18 
Table 4: Quantification frequency and median concentration of the targeted surfactants in 36 river waters sampled in France in 2018

\begin{tabular}{|c|c|c|c|}
\hline Substance & $\begin{array}{c}\text { Number of positive } \\
\text { samples }(n=36)\end{array}$ & $\begin{array}{l}\text { Quantification } \\
\text { frequency }(\%)\end{array}$ & $\begin{array}{c}\text { Median concentration } \\
(\mu \mathrm{g} / \mathrm{L})\end{array}$ \\
\hline LAS C 10 & 34 & 94 & 0.714 \\
\hline LAS C11 & 35 & 97 & 4.63 \\
\hline LAS C12 & 35 & 97 & 3.81 \\
\hline LAS C13 & 33 & 92 & 2.36 \\
\hline LAS C14 & 0 & 0 & $<\mathrm{LQ}$ \\
\hline $\mathrm{C}_{12} \mathrm{EO}_{1} \mathrm{~S}$ & 3 & 8 & 1.14 \\
\hline $\mathrm{C}_{12} \mathrm{EO}_{2} \mathrm{~S}$ & 1 & 3 & 0.898 \\
\hline SDS & 3 & 8 & 0.480 \\
\hline EHS & 9 & 25 & 0.140 \\
\hline $\mathrm{OP}_{7} \mathrm{EO}$ & 1 & 3 & 0.024 \\
\hline $\mathrm{OP}_{8} \mathrm{EO}$ & 1 & 3 & 0.024 \\
\hline $\mathrm{OP}_{9} \mathrm{EO}$ & 1 & 3 & 0.024 \\
\hline $\mathrm{OP}_{10} \mathrm{EO}$ & 1 & 3 & 0.024 \\
\hline $\mathrm{OP}_{11} \mathrm{EO}$ & 1 & 3 & 0.024 \\
\hline CMEA & 1 & 3 & 0.254 \\
\hline TMDD & 9 & 25 & 0.347 \\
\hline $\mathrm{BAC}-\mathrm{C}_{12}$ & 0 & 0 & $<\mathrm{LQ}$ \\
\hline $\mathrm{BAC}-\mathrm{C}_{14}$ & 0 & 0 & $<\mathrm{LQ}$ \\
\hline DDAC-C 10 & 1 & 3 & 0.074 \\
\hline LaurPyr & 1 & 3 & 0.043 \\
\hline TEAQ-C 16 & 0 & 0 & $<\mathrm{LQ}$ \\
\hline TEAQ-C$_{18}$ & 0 & 0 & $<\mathrm{LQ}$ \\
\hline TEAQ-C 18 sat. & 0 & 0 & $<\mathrm{LQ}$ \\
\hline SADP-DMA & 0 & 0 & $<\mathrm{LQ}$ \\
\hline Cetylbetaine & 0 & 0 & $<\mathrm{LQ}$ \\
\hline
\end{tabular}

